\title{
Industrial precipitation of yttrium chloride and zirconyl chloride: Effect of pH on ceramic properties
}

\section{for yttria partially stabilised zirconia}

G. A. Carter, ${ }^{a+b}$ R. D. Hart ${ }^{b}$, M. Rowles ${ }^{c}$ M. I. Ogden ${ }^{a *}$ and C. E. Buckley ${ }^{b}$

${ }^{a}$ Nanochemistry Research Institute, Curtin University of Technology, PO Box U1987, Perth, Western Australia, 6845, Australia

${ }^{b}$ Centre for Materials Research, Curtin University of Technology, PO Box U1987, Perth, Western Australia, 6845, Australia

${ }^{c}$ Commonwealth Scientific, Industrial Research Organisation (CSIRO), Minerals Division, Clayton Vic

\section{Abstract}

Two 3 mol\% partially stabilised zirconia (P-SZ) samples suitable for the SOFC market were manufactured from solutions through to ceramics using a method similar to a known industrial process. The only difference in preparation of the two $3 \mathrm{~mol} \%$ P-SZ samples was the $\mathrm{pH}$ of precipitation which was set at $\mathrm{pH} 3$ or 12 . Particle size measurements by dynamic light scattering were used to characterise the precipitate and the filtration rates were investigated. Five point $\mathrm{N}_{2}$-BET was used to investigate the specific surface area before and after calcination with the response to temperature tracked. Similarly TGA/DTA investigation was used to determine the calcination

Corresponding Author current affiliation: Nanochemistry Research Institute, Curtin University of Technology, PO Box U1987, Perth, Western Australia, 6845, Australia Tel:- +61 89266 2483, Fax:- +61 892664699 Email:- m.ogden@curtin.edu.au 
point during all of these tests and it was found that both powders behaved similarly. XRD-Rietveld analysis incorporating in-situ and ex-situ calcination revealed that the pH 3 sample had more monoclinic phase present after calcination and sintering as a ceramic. Ceramic testing incorporating hardness (Vickers), toughness $\left(\mathrm{K}_{1 \mathrm{C}}\right)$, MOR, density and grain sizing was carried out, all determined that the material produced at $\mathrm{pH} 12$ was superior for SOFC applications than the $\mathrm{pH} 3$ sample. Further investigation using TEM-EDS revealed that the processing of the $\mathrm{pH} 3$ powder had allowed a lower concentration of the yttrium which was incorporated at approximately 2 mol\% instead of the required 3. ICP-OES of the after-filter liquor indicated that high concentrations of yttrium $(797 \mathrm{ppm})$ were found in the solution with the wash solution having $149 \mathrm{ppm}$ yttrium. In contrast the $\mathrm{pH} 12$ samples had 7 ppm in both the after filter liquor and wash indicating that the yttrium is bound within the matrix more completely at the higher $\mathrm{pH}$.

Keywords: Zirconia; yttrium; ceramics; precipitation; calcination 


\section{Introduction}

Zirconia and yttria-doped zirconia are important technological ceramic materials. As part of an on-going research program we have been investigating the fundamental chemistry of the processing of these materials, with a core focus on industrially relevant aqueous processing. Here we are using zirconyl chloride and investigating how the aqueous processing changes might affect the ceramic performance.

Previous publications by the group have highlighted differences in the aqueous processing of both un-doped and doped zirconia in the through-processing of the wet chemistry. Small Angle X-ray Scattering (SAXS) of zirconyl chloride solution speciation demonstrated changes with solution concentration and doping levels. This work found few changes were evident by increasing the solution concentration from $0.81 \mathrm{M}$ to $1.62 \mathrm{M}$, however a trend was noticed with increasing yttrium chloride concentration from 3 mol\% to 10 mol\% [1]. Dynamic Light Scattering (DLS) characterising the precipitates obtained at $\mathrm{pH} 6$ demonstrated that significant particle growth was observed upon doubling the concentration and enhanced particle growth was also seen upon the introduction of doping elements, in particular yttrium [1].

Further work focused on process changes found that significant differences in precipitated particle size were caused by both the $\mathrm{pH}$ of precipitation and the agitation level. Investigations of materials produced at $\mathrm{pH} 3$ and 12, using TGA/DTA, microcombustion and TEM EDS, found that the precipitated zirconium hydroxide had different structures, with the $\mathrm{pH} 3$ sample giving results consistent with a formulation 
of $\mathrm{Zr}[\mathrm{OH}]_{4}$ while the $\mathrm{pH} 12$ sample was consistent with $\mathrm{ZrO}[\mathrm{OH}]_{2}$ [2] . Previous work conducted on the through-processing has in the main concentrated on un-doped zirconia and demonstrated that there were differences evident in the ceramics made from zirconia produced at the different $\mathrm{pH}$ values [3]. Carter et. al. [1-3] outline a number of authors who have similarly found the performance of zirconia dependent on the process used in its manufacture.

The major focus of this research was to facilitate the industrial processing of zirconia for Solid Oxide Fuel Cell (SOFC) applications and therefore we have focused on the through-processing and ceramic properties of a $3 \mathrm{~mol} \%$ yttria zirconia which is commonly called 3 mol\% Yttria Partially Stabilised Zirconia (3 mol\% Y-PSZ). The current work follows the processing steps from precipitation through to general ceramic testing to compare the differences between ceramics obtained from powders manufactured at $\mathrm{pH} 3$ with those produced at $\mathrm{pH} 12$.

The engineering/physical properties of zirconia have been thoroughly reviewed [4], [5]. SOFC are devices for converting hydrogen (or natural gas) and oxygen into water with a resulting generation of electrical power. The obvious difference between a SOFC and other fuel cells is that the major component in the anodes, cathodes and electrolytes are entirely or partially made from an oxide ceramic. Badwal and Foger [6] detail that SOFC electrolytes must not only have high oxygen-ion ionic conductivity but must also be stable with respect to other cell components, and have the mechanical properties such as strength, toughness, creep and thermal shock resistance. SOFC place high demands on both the materials that they are manufactured from and the manufacturing method. In addition, the components themselves are required to have good ionic/electrical properties and be able to 
withstand high operating temperatures while maintaining the mechanical properties required for typical life times of 40,000 - 50,000 hours [6].

Most SOFC manufacturers/developers are using zirconia doped with yttria as the electrolyte with variations in the amount of yttria [7]. The physical characteristics of precursor powders for the manufacture of a planar SOFC have been discussed by Bellon et. al. and Ahmed et al. [8, 9]. Carter et. al.[10] showed that the process of coprecipitation of three initially mixed chlorides, alumina chloride, yttrium chloride and zirconium chloride, can produce an oxide powder that has a homogeneous distribution of all three constituents. This homogeneity in solid solution allows for greater control of the zirconia polymorphs, leads to better processing ability in the manufacture of the parts of the SOFC, and because of a lack of concentration gradients in the finished material is likely to lead to better lifetimes.

McEvoy [11] states that the ideal solid electrolyte was identified by Nernst as zirconium oxide with a mixture of di- or trivalent substitutes in solid solution, with the $8 \%$ yttria-zirconia being preferred. 3 mol\% Y-PSZ has subsequently been found to be better due to its inherent mechanical strength [12] [6]. SOFC manufacturers have investigated a range of novel formulations often with other elements substituting for yttria [12-18]. Ciacchi et. al. [7] supply comparative chemical, XRD phase composition, sintered density, grain size and conductivity data for five commercially produced 3 mol\% Y-PSZ, providing bench mark information for any prospective commercial producer of $3 \mathrm{~mol} \%$ Y-PSZ for SOFC applications, although no information as to how they are made are given.

\section{Experimental Procedures}


Solution preparation, precipitation, milling and particle sizing by DLS, were carried out as reported previously [1] [3], with further details contained in the supplementary information. It is of note that precipitation was carried out in line with a local manufacturer's technology that is of a proprietary nature [10].

After milling to a particle size ranging from 15 to $42 \mu \mathrm{m}$ the slip was spray dried using a binder.

Sintered sample characterisation as well as in situ calcination studies were conducted using X-Ray Diffraction (XRD) with the patterns being analysed using Rietveld refinement (full experimental details are contained in the supplementary information).

The physical testing of the 3 mole \% yttria-zirconia matrix was carried out using a range of standard or well known tests, as described in the supplementary information. 


\section{Results}

We have previously studied the precipitation of zirconia in the absence of yttrium, and found that $\mathrm{pH}$ has a significant impact on the nature of the precipitate [1] [2]. The conditions used here (Table 1) are based on this earlier work. It was immediately noted that with the added yttrium, the differences in particle size (Table 1) as a function of $\mathrm{pH}$ are much smaller than found for the pure zirconia system [2].

Table 1 Wet chemistry conditions and physical properties (PS is mean diameter by peak intensity)

\begin{tabular}{|c|c|c|c|c|c|}
\hline $\mathrm{pH}$ & $\begin{array}{c}\text { Concentration of } \\
\text { starting } \\
\text { solutions }\end{array}$ & $\begin{array}{c}\text { Agitation } \\
\text { level }\end{array}$ & PS $(\mu \mathrm{m})$ & Filtration & SSA (m $\left.{ }^{2} / \mathrm{g}\right)$ \\
& 0.81 & High & $2.7(1)$ & 5 & $197(5)$ \\
\hline 3 & 0.81 & High & $1.8(2)$ & 7 & $215(3)$ \\
\hline 12 & & & & & \\
\hline
\end{tabular}

Figure 1 shows the TGA/DTA trace for both the $\mathrm{pH} 3$ and the $\mathrm{pH} 12$ samples. The calcination point for both samples was approximately $400^{\circ} \mathrm{C}$ with a weight loss of around $43 \%\left(\mathrm{pH} 3405^{\circ} \mathrm{C}, 42.4 \mathrm{wt} \%\right.$ and $\mathrm{pH} 12,393^{\circ} \mathrm{C}$ and $\left.44.2 \mathrm{wt} \%\right)$. Once again, the change in $\mathrm{pH}$ is found to induce a much smaller change than found in the pure zirconia system; previously the authors reported that a marked difference exists between zirconium hydroxide precipitated at differing $\mathrm{pH}$ values [2]. For a non stabilised zirconia system the maximum weight loss was $32.5 \mathrm{wt} \%$ assigned to a transformation of $\mathrm{ZrO}[\mathrm{OH}]_{2}$ to $\mathrm{ZrO}_{2}$. In this case the mass loss is significantly greater for what in relative terms is a small amount of added yttrium. One explanation for this 
is that the additional yttrium has changed the surface charge such that less water is driven off during the drying process prior to the TGA/DTA analysis.

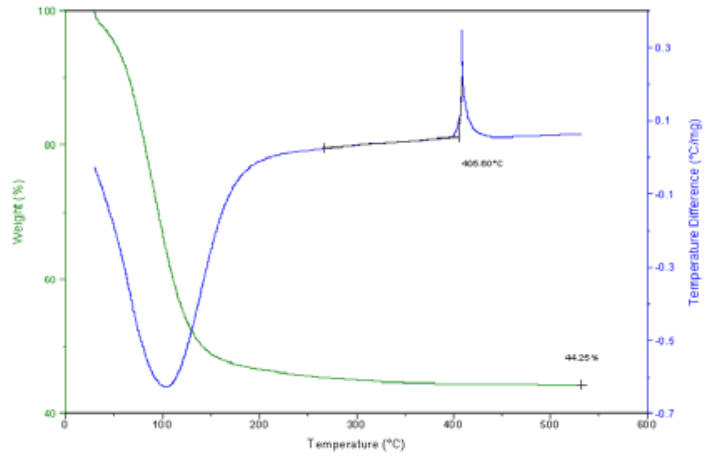

(a)

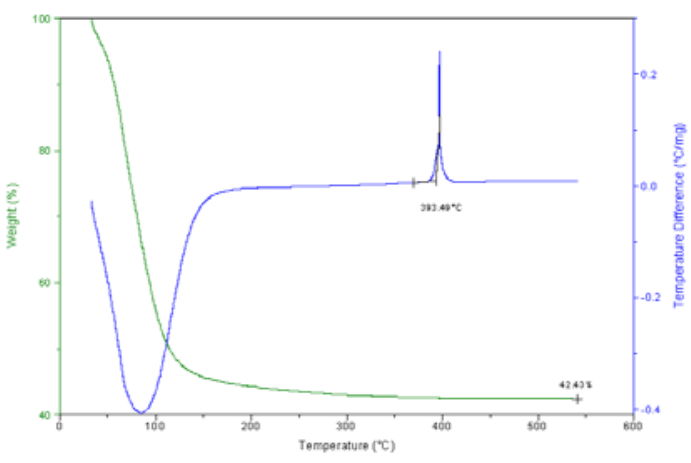

(b)

Figure 1 TGA/DTA trace (a) pH 3 sample (b) pH 12 sample

Figure 2 shows the $\mathrm{x}$-ray diffraction patterns for the $\mathrm{pH} 12$ sample during the calcination; Figure 3 shows the plots for the $\mathrm{pH} 3$ sample. The transformation temperature differences observed between the TGA/DTA and the x-ray diffraction are assumed to be due to experimental differences, with sample size, temperature steps with holds and temperature measuring systems all contributing. A typical pattern fit from the Rietveld analysis to determine the phase compositions of the samples with temperature is shown in Figure 4. The results of the phase analysis are shown in Figure 5, the phase composition \% does not appear to change once the maximum tetragonal phase has been obtained. Here some differences with $\mathrm{pH}$ are observed; for the $\mathrm{pH} 3$ precipitated samples the maximum is approximately $75 \%$, whilst for the $\mathrm{pH}$ 12 samples it is approximately $90 \%$. 


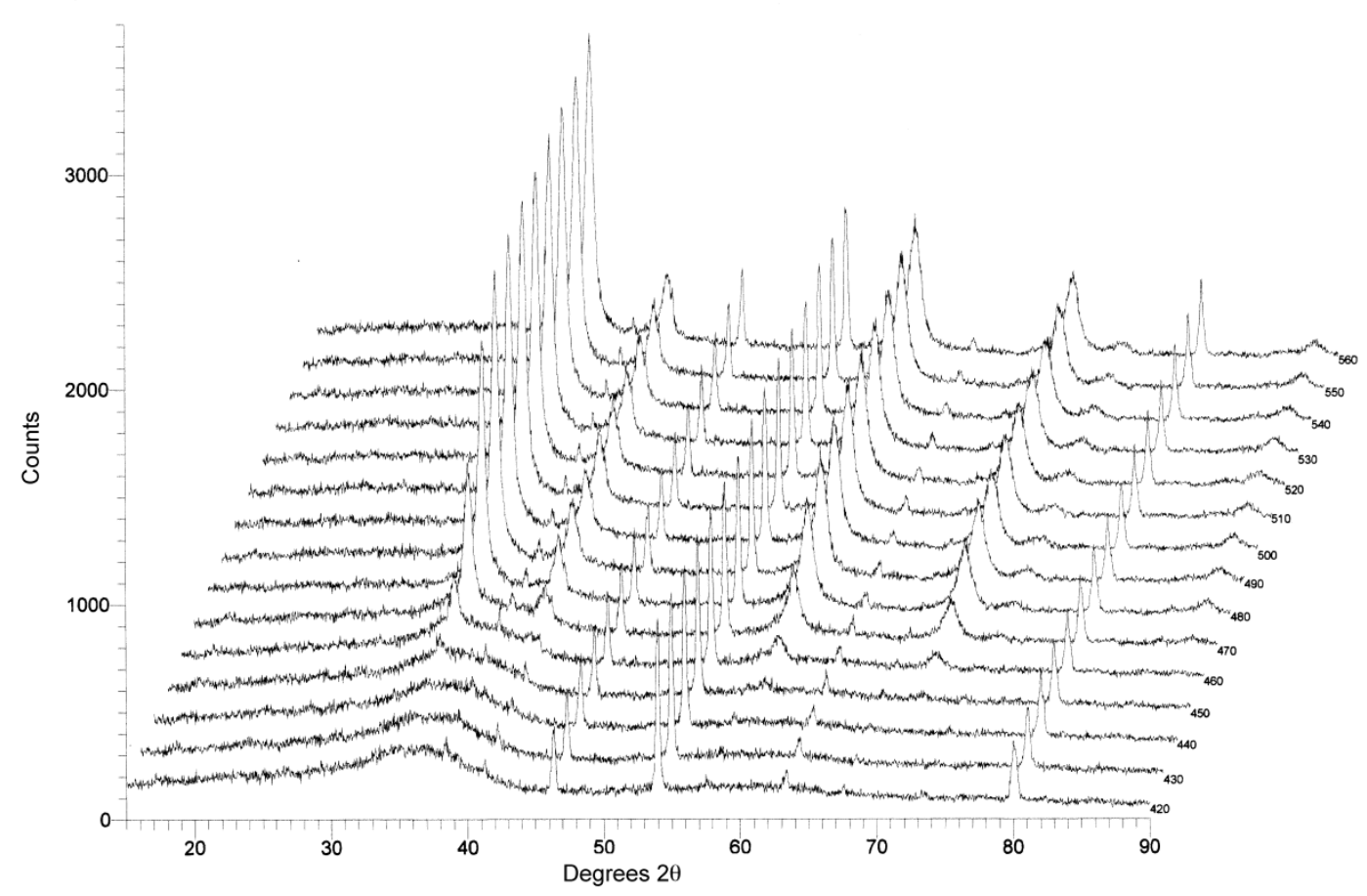

Figure 2. XRD plots with increasing temperature through calcination, $\mathrm{pH} 12$ sample

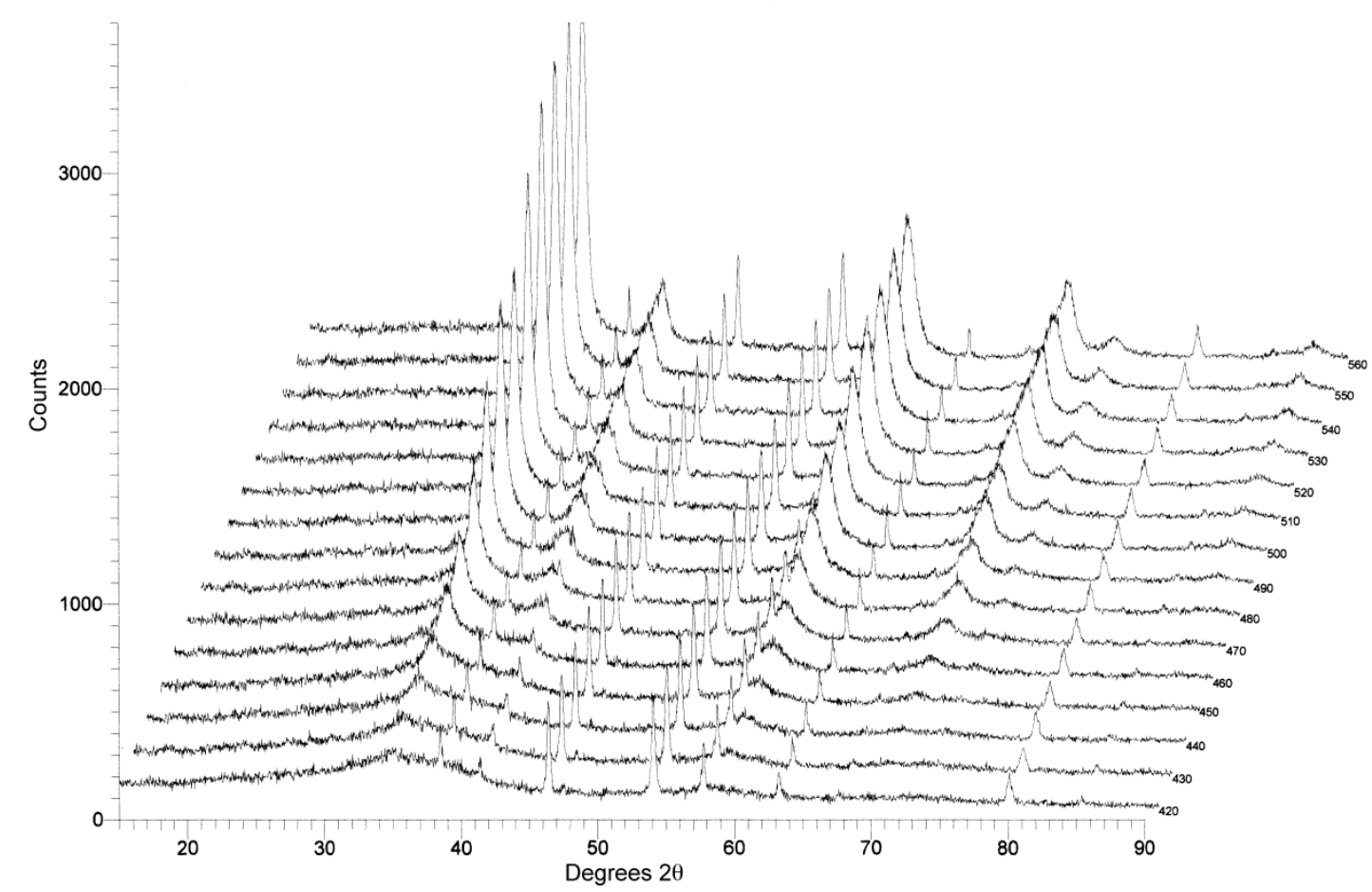

Figure 3. XRD plots with increasing temperature through calcination, $\mathrm{pH} 3$ sample 


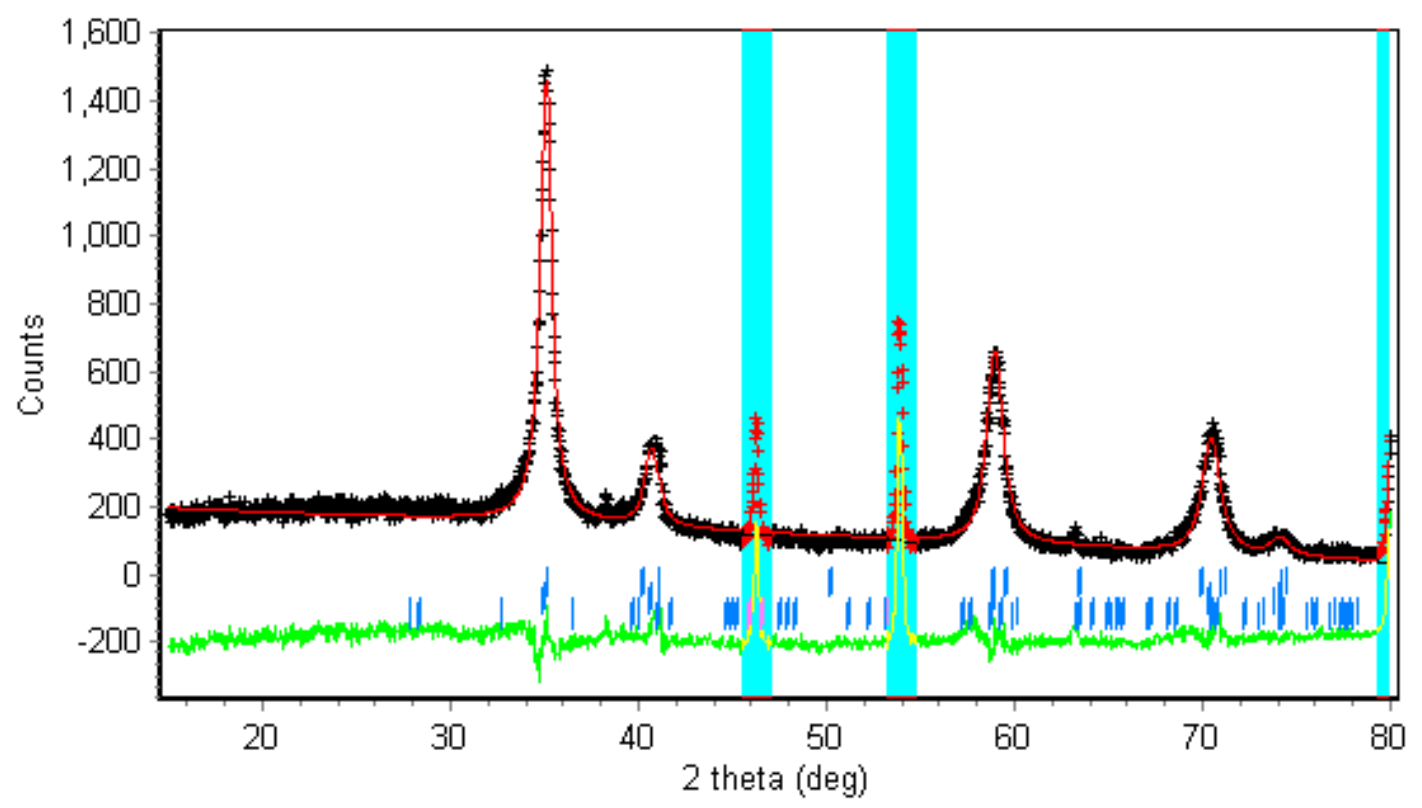

Figure 4. Rietica plot pH 12 sample @ 580 $\mathrm{C}$ (the regions of exclusion are peaks due to Pt strip heater/sample holder).

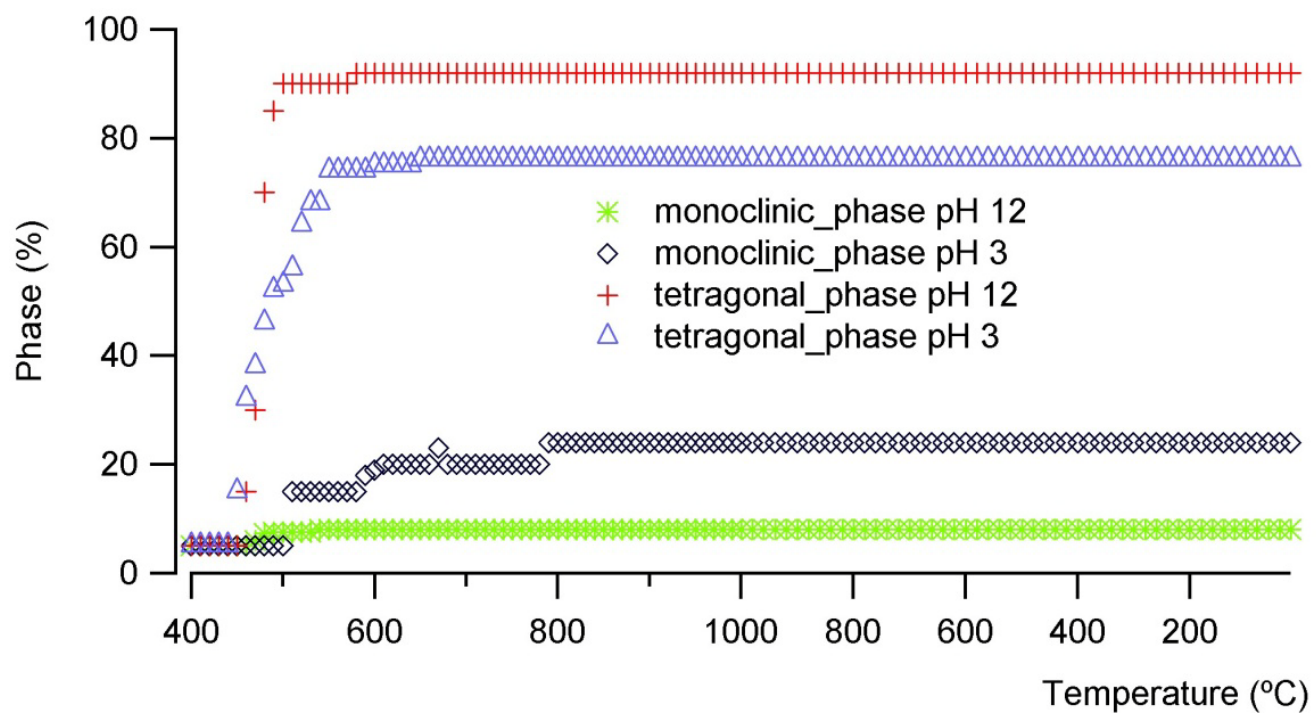

Figure 5. Phase composition for both samples with temperature (all uncertainties for both phases are 3\%) 
TEM microscopy (Figure 6) found that a crystallite size of $18 \mathrm{~nm} \pm 5 \mathrm{~nm}$ within a larger aggregate was typical for both powders. The specific surface area (SSA) response with calcination was also similar, showing a linear decrease from approximately $700{ }^{\circ} \mathrm{C}$ until $1100{ }^{\circ} \mathrm{C}$ (Figure S 3).

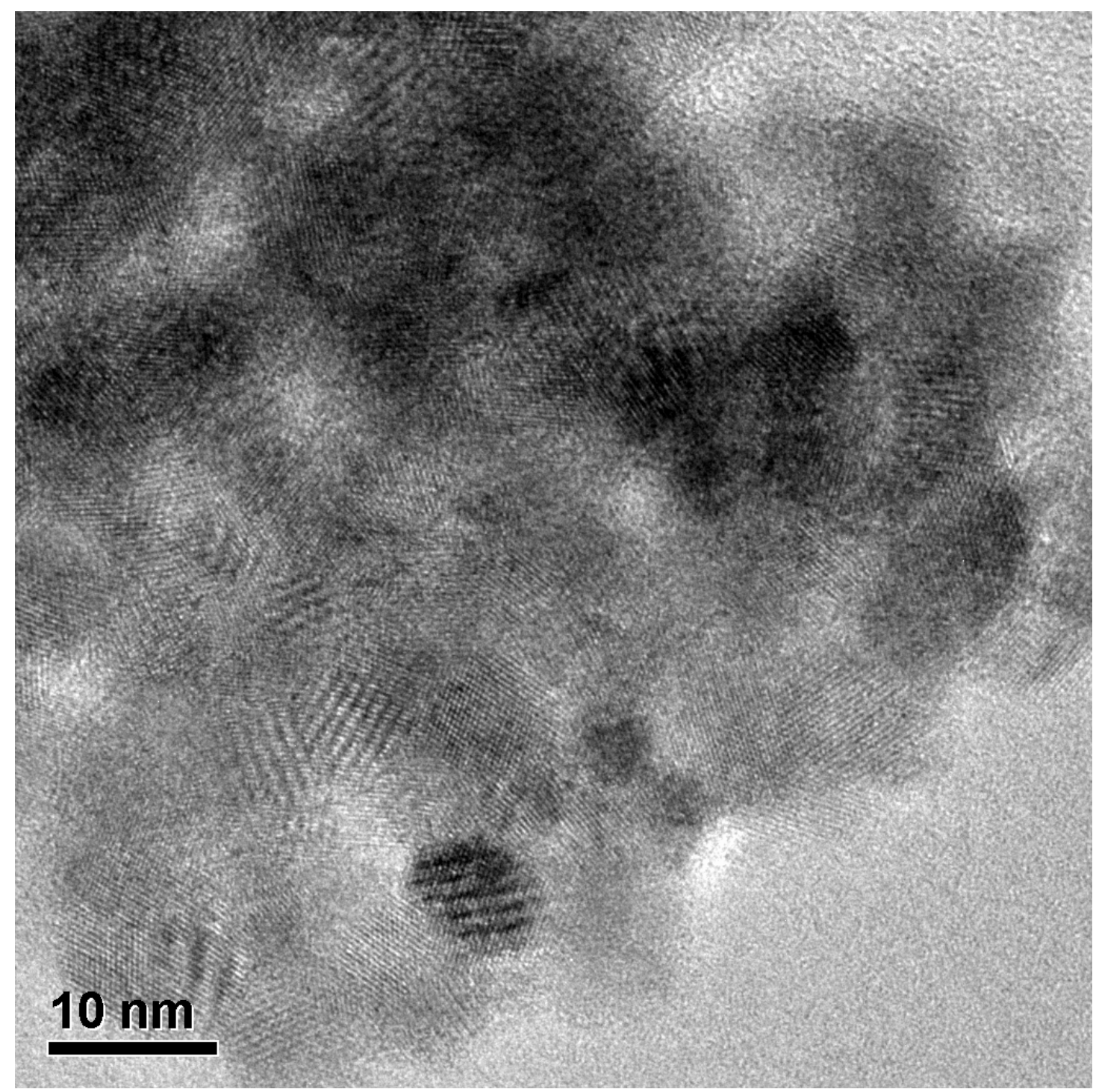

Figure 6. pH 12 sample TEM image showing lattice planes

Attrition milling curves for samples of powders calcined at $1000^{\circ} \mathrm{C}$ were similar for the last 7 hours of milling with the total time of 22 hours in both cases. The responses in the first 10 hours do vary, with the $\mathrm{pH} 3$ sample D90 reducing more slowly than 
that of the $\mathrm{pH} 12$, as also found for unstabilised zirconia [3]. Full milling curves are contained in the supplementary information (Figure S 1 and Figure S 2).

The sintered density of 3 mol\% Y-PSZ samples is reported to be between 6.04 and 6.08 g.cm ${ }^{-3}$ [7] [13]. Varying densities have been reported for commercial samples sintered at 4 different temperatures, [14] and a similar firing regime was used here. The results (Table 2) show that the sintered densities for the $\mathrm{pH} 3$ samples are between 5.88 g.cm ${ }^{-3}$ and 5.80 g.cm ${ }^{-3}$ with those of the $\mathrm{pH} 12$ samples between 6.01 and $6.08 \mathrm{~g} . \mathrm{cm}^{-3}$, depending on thermal treatment.

Table 2. Sintering temperature vs density and \% linear shrinkage (uncertainties are std. deviation of 5 samples)

\begin{tabular}{|l|l|l|l|l|}
\hline Sintering temperature & $\begin{array}{l}\mathrm{pH} 3 \text { Density } \\
\left(\mathrm{g} / \mathrm{cm}^{3}\right)\end{array}$ & $\begin{array}{l}\text { \% Linear } \\
\text { shrinkage }\end{array}$ & $\begin{array}{l}\mathrm{pH} 12 \text { Density } \\
\left(\mathrm{g} / \mathrm{cm}^{3}\right)\end{array}$ & $\begin{array}{l}\text { \% Linear } \\
\text { shrinkage }\end{array}$ \\
\hline 1650 & $5.85(1)$ & $20(3)$ & $6.04(2)$ & $20(2)$ \\
\hline 1550 & $5.88(1)$ & $24(1)$ & $6.08(2)$ & $25(1)$ \\
\hline 1450 & $5.86(2)$ & $21(3)$ & $6.03(2)$ & $20(4)$ \\
\hline 1350 & $5.80(5)$ & $19(2)$ & $6.01(4)$ & $20(3)$ \\
\hline
\end{tabular}

The density of the pH 3 sample was considerably lower than literature values, and various causes for this were considered. It has been suggested that less than optimal densities can be caused by the powder compacts containing hard agglomerates from the powder processing [15]. The strength of the spray-dried agglomerates was investigated using a literature method [16] and the powders were found to be the same, (a SEM micrograph of a typical spray-dried agglomerate can be seen in Figure S 4). Another explanation could be the porosity in the ceramic but the grain sizing micrographs showed little evidence of this (see Figure $S 5$ for typical grain sizing 
micrograph). Investigations of the porosity of yttria-zirconia ceramics have been conducted to good effect in this manner previously [17].

The linear shrinkage for 3 mol\% Y-PSZ is reported to be $27 \%$ [18]. The values listed in Table 2 for the maximum density are slightly lower at 24 and 25\% for the $\mathrm{pH} 3$ and 12 samples respectively.

Table 3 shows the other physical properties obtained from the testing of the samples. The grain size of the two samples revealed that the two powders ( $\mathrm{pH} 3$ and $\mathrm{pH} 12$ ) are similar. Grain size is linked with surface flatness of tape cast parts, with grain sizes up to $10 \mu \mathrm{m}$ producing "excellent" flatness [8]. SEM micrographs of the powders produced here show grain sizes well below the $10 \mu \mathrm{m}$ range. A reported generalisation is that the grain size of YSZ materials with less than $8.5 \mathrm{~mol} \%$ yttria is usually larger than $5 \mu \mathrm{m}$ [12]. Other reports, however, give grain sizes of approximately $0.6 \mu \mathrm{m}$ [7] [14] [19]. A rather novel but simple experiment [20] showed that exaggerated growth of grains can be attributed to variation in yttria concentrations within the system, and hence the relatively small particle size distribution within the two samples in this work may indicate a relatively uniform or homogenous yttria distribution, which is an advantage of the co-precipitation method used to prepare the samples.

Hardness of the Y-SZ determined using Vickers indentation is shown in Table 3. Figure S 6 shows a typical optical micrograph of an indentation observed in this work. The resulting values are consistent with the literature [6] [21] [22]. Kondoh et. al. [23] lists lower densities and higher hardness and toughness values for ceramics with 
lower yttrium levels. In Hsieh and Tuan [21] the value for the hardness and toughness for $3 \mathrm{~mol} \% \mathrm{Y}$-PSZ is $13.1 \pm 0.2 \mathrm{GPa}$ and $4.5 \pm 0.2 \mathrm{MPa}^{1 / 2}$ for a mixture of coprecipitated 8 mol\% YSZ with pure zirconia powder co-milled to form 3 mol\% YPSZ. The increased hardness is suggested to be a result of the uneven distribution of yttria [21], the materials examined in the present work have lower hardness values but have higher toughness values. Hsieh and Tuan [21] used the $\mathrm{K}_{1 \mathrm{C}}$ method to determine the hardness, which is the same method employed here following literature procedures [24]. However, Kruzic and Ritchie [25] suggest that this may not be suitable due to secondary cracking which is evident in Figure $S$. The $K_{1 C}$ method has nevertheless been used for this work as results using the method suggested by Kruzic and Rictchie [25] are rarely reported.

Kondoh et. al. [23] list tensile strength against the yttria content for commercially available Y-SZ and Y-PSZ . They found that the tensile strengths of 2.6, 3 and 4 mol \% Y-PSZ were the same. They also found $\mathrm{K}_{1 \mathrm{C}}$ fracture toughness values of for the 2.6 and $3 \mathrm{~mol} \%$ samples of $5 \mathrm{MPa} \cdot \mathrm{m}^{1 / 2}$ and the $4 \mathrm{~mol} \%$ had a value closer to $6 \mathrm{MPa} \cdot \mathrm{m}^{1 / 2}$. These values are comparable with those determined here (Table 3).

Table 3 Physical properties of ceramics (fired at $1550^{\circ} \mathrm{C}$ ).

\begin{tabular}{|c|c|c|}
\hline & $\mathrm{pH} \mathrm{3}$ & $\mathrm{pH} \mathrm{12}$ \\
\hline Grain Size $(\mu \mathrm{m})$ & $2(2)$ & $2(2)$ \\
\hline Hardness $(\mathrm{GPa})$ & $12.60(8)$ & $12.46(3)$ \\
\hline Toughness $\left(\mathrm{MPa} \cdot \mathrm{m}^{1 / 2}\right)$ & $6.32(9)$ & $6.78(7)$ \\
\hline MOR $(\mathrm{GPa})$ & $0.81(7)$ & $1.02(3)$ \\
\hline Weibull modulus & 9.68 & 13.34 \\
\hline
\end{tabular}


A comparison of the bars manufactured for the Modulus Of Rupture (MOR) test showed that their optical properties appeared to be different (Figure S 7), although the reason for this is not apparent at this stage. The value of $1.02 \mathrm{GPa}$ developed for the pH 12 sample exceeds that listed by Badwal and Foger [6]. However these authors also list $900 \mathrm{MPa}$ as the lower limit, which the $\mathrm{pH} 3$ sample does not reach. The minimum Weibull modulus requirement for a modern engineering ceramic is 9.7 which both samples achieved (pH $12=13.34, \mathrm{pH} 3=9.86$, Table 3) [26]. Figure 7 is a typical micrograph of the fractured surface of the MOR bars showing there were no indications of poor forming or sintering in either sample.

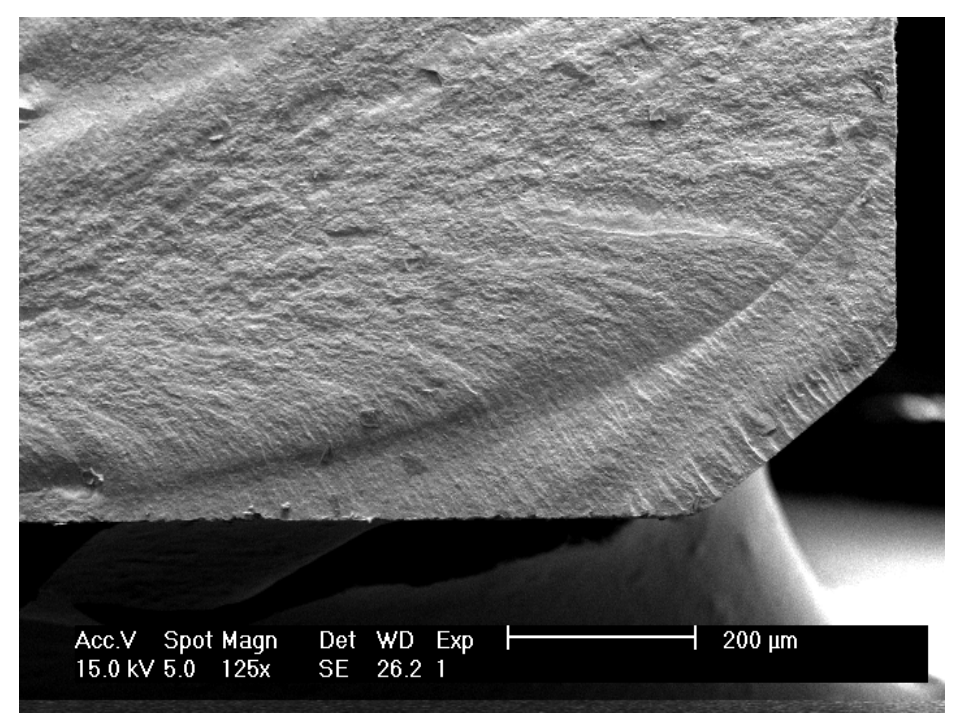

Figure 7 MOR bar broken surface showing chamfer (pH 12)

Figure 8 shows the XRD traces for the sintered ceramics of both samples, the differences are mainly the presence of higher concentrations of monoclinic phase in the $\mathrm{pH} 3$ sample compared to the $\mathrm{pH} 12$ sample. The hump at $28.44^{\circ} 2 \theta$ in Figure 8 is similar to the literature result for a $2.6 \%$ sample [27] suggesting the $\mathrm{pH} 3$ sample may have this composition. This hypothesis was tested by TEM EDS analysis. 


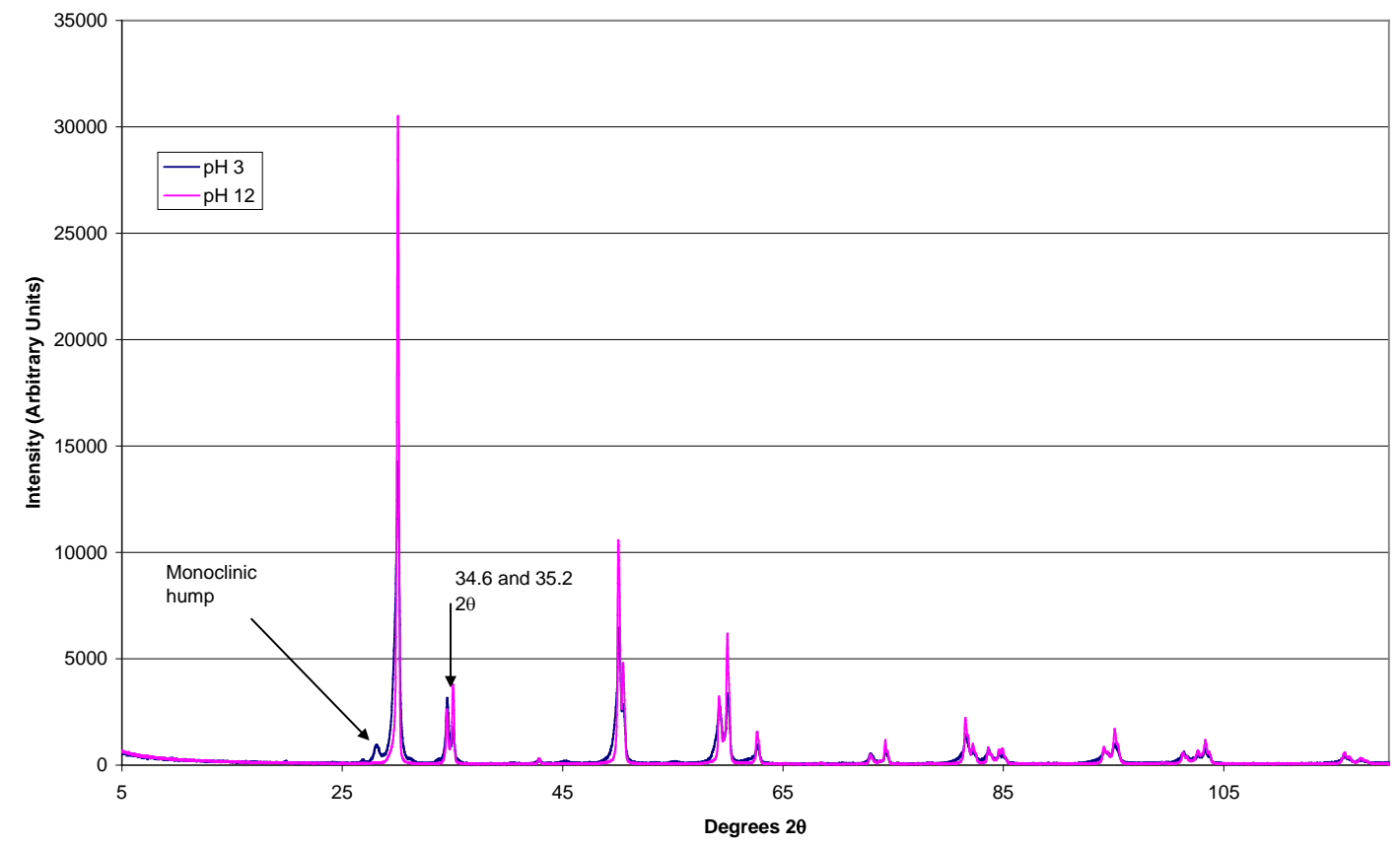

Figure 8 XRD of the sintered ceramics

TEM EDS determined yttria values for the two samples were 3.3(8) wt\% for $\mathrm{pH} 3$ and 5.5(4) wt\% for $\mathrm{pH}$ 12, (equivalent to 1.8 and $3 \mathrm{~mol} \%$; figures in brackets are the uncertainties in the last decimal place from the standard deviation of 20 sample points). The difference was unexpected as both samples were produced from the same initial solution compositions.

Literature values [13] for the densities of 1.7, 2.2, 2.8 and 3.1 mol\% Y-PSZ are given as 5.842, 6.044, 6.085 and $6.077 \mathrm{~g} / \mathrm{cm}^{3}$ (measured). In this work, the $\mathrm{pH} 3$ sample returned a density of $5.88 \mathrm{~g} / \mathrm{cm}^{3}$ and the $\mathrm{pH} 12$ gave $6.08 \mathrm{~g} / \mathrm{cm}^{3}$. This would suggest that the pH 3 sample had between 1.7 and 2.2 mol\% yttria consistent with the TEM EDS result of 2 mol\%. 
Subsequent testing of the liquor after passing through the filter and of the wash solution using ICP-OES indicated that minimal yttrium is lost from the $\mathrm{pH} 12$ processing, however the $\mathrm{pH} 3$ sample had high levels of yttrium in the liquor as well as the wash (Table 4). This would indicate that the yttrium is not precipitating out under the acidic conditions in such a way as to be tightly bound within the zirconium matrix thus allowing it to be lost in the subsequent processing steps. This is a significant finding as the industrially relevant process that this research is based upon uses formation in the acidic region.

Table 4 ICP-OES results of liquor and wash for yttrium

\begin{tabular}{|c|c|}
\hline Sample & $\mathrm{Y} \mathrm{(ppm)}$ \\
\hline pH 3 liquor & 797 \\
\hline $\mathrm{pH} \mathrm{3} \mathrm{Wash}$ & 149 \\
\hline $\mathrm{pH} \mathrm{12} \mathrm{liquor}$ & 7 \\
\hline $\mathrm{pH} \mathrm{12}$ wash & 7 \\
\hline
\end{tabular}

\section{Conclusions}

Two Y-PSZ powders were produced using the same initial chemical mix and the same processing with the exception of $\mathrm{pH}$ of precipitation, and both were processed through to ceramics. The two $\mathrm{pH}$ values used were 3 and 12 and throughout the processing the two samples behaved remarkably similarly. The precipitated particle sizes, filtration rate and SSA for the pH 3 sample was found to be 2.7(1) $\mu \mathrm{m}, 5$ minutes and 197(5) $\mathrm{m}^{2} / \mathrm{g}$ while the $\mathrm{pH} 12$ sample had $1.8(2) \mu \mathrm{m}, 7$ minutes and $215(3) \mathrm{m}^{2} / \mathrm{g}$, both samples calcining at approximately $400^{\circ} \mathrm{C}$. In situ XRD used to determine the phase evolution with temperature from $350^{\circ} \mathrm{C}$ through to $1000^{\circ} \mathrm{C}$ and returning to room temperature 
which showed that the $\mathrm{pH} 3$ sample obtained approximately $75 \%$ tetragonal phase whilst the pH 12 sample obtained 90\% tetragonal phase. The total milling time for both samples was 22 hours although slight differences were noted in the milling curves. The spray dried mill slip produced a free flowing powder for both samples that when investigated using SEM and powder compaction methods showed a well formed and regular powder.

The mechanical properties of the final sintered ceramics showed differences in the results for density, hardness, toughness and MOR measurements. The $\mathrm{pH} 3$ sample was harder but had lower toughness and MOR than the pH 12 sample. Differences in the XRD patterns of the final sintered ceramic were noted with the $\mathrm{pH} 3$ sample having higher levels of the monoclinic phase. The similarity of the $\mathrm{pH} 3$ sample to that in literature for a 2.6 mol\% Y-PSZ suggested that the yttrium level was lower than expected from the starting solution concentrations. TEM-EDS investigation revealed that the $\mathrm{pH} 3$ precipitated sample had 3.3(8) wt\% and $\mathrm{pH} 12=5.5(4) \mathrm{wt} \%(\approx$ 2 and 3 mol\% respectively). This difference in yttria content explains the differences in the mechanical properties with the density of the $\mathrm{pH} 3$ sample matching well to the theoretical density of a powder made from between 1.7 to 2.2 mol\% Y-PSZ.

Subsequent testing using ICP-OES indicated that when the processing is conducted at $\mathrm{pH}$ 3, high levels (797 ppm) of yttrium are found in the liquor after filtering with lower levels (149 ppm) found in the wash solution after filtering. In contrast only 7 ppm was found in both the liquor and wash for the $\mathrm{pH} 12$ precipitated sample. Precipitation at such low $\mathrm{pH}$ for Y-PSZ powders is not feasible as the loss of yttrium 
in the filtering and washing of precipitate adversely affects the final properties of the ceramic.

Comparisons made to products currently available in the market for use in SOFC manufacture indicate that the process used to produce the $\mathrm{pH} 12$ sample would be suitable for the manufacture of SOFC.

Acknowledgements

G.C, C.B. and M.O. acknowledge the financial support of the Australian Research Council (ARC) for ARC linkage grant LP0561922. G.C. is the holder of an Australian Postgraduate Award (Industry) and AINSE Postgraduate Research Award.

\section{References}

[1] G. A. Carter, M. I. Ogden, C. E. Buckley, C. Maitland, M. Paskevicius, Powder Technology, In Press, Corrected Proof doi:10.1016/j.powtec.2008.04.087.

[2] Carter G., M. Rowles, Hart R., Ogden M., Buckley C., Powder Technology 2008, In Press.

[3] Carter G., M. Rowles, Hart R., Ogden M., Buckley C., Materials Forum 2008, 32-2008, 82.

[4] R. H. J. Hannink, P. M. Kelly, B. C. Muddle, J. Am. Ceram. Soc. 2000, 83, 461.

[5] D. J. Green, R. H. J. Hannink, M. V. Swain, Transformation Toughening of Ceramics, CRC Press, Inc.,, Florida.

1989.

[6] S. P. S. Badwal, K. Foger, Materials Forum 1997, 21, 187.

[7] F. T. Ciacchi, K. M. Crane, S. P. S. Badwal, Solid State Ionics 1994, 73, 1994.

[8] O. Bellon, R. Ratnaraj, D. Rodrigo, "10YSZ based electrolyte materials for electrolyte supported SOFCs", presented at 5th European SOFC Forum, Proceedings, 2002.

[9] K. Ahmed, J. Love, R. Ratnaraj, "High Performance Cell Development at CFCL", presented at Electrochemical Society Proceedings 2001.

[10] G. A. Carter, R. D. Hart, N. M. Kirby, D. Milosevic, A. N. TiTkov, J. Australas. Ceram. Soc. 2003, 39, 149.

[11] A. J. McEvoy, J. Mater. Sci. 2001, 36, 1087.

[12] S. P. S. Badwal, F. T. Caicchi, Ionics 2000, 6, 1.

[13] R. Ingel, D. Lewis, J. Am. Ceram. Soc. 1986, 69, 325.

[14] S. P. S. Badwal, F. T. Ciacchi, K. M. Giampietro, Solid State Ionics 2005, $176,169$.

[15] O. C. Standard, C. C. Sorrell, Key Engineering Materials 1998, 153-154, 251. 
[16] R. L. K. Matsumoto, J. Am. Ceram. Soc. 1986, 69, C.

[17] A. G. Mawson, G. A. Carter, R. D. Hart, N. M. Kirby, A. C. Nachmann, Materials Forum 2006, 30, 148.

[18] S. K. Tadokoro, E. N. S. Muccillo, J. Alloys. Compd. 2002, 344, 186.

[19] S. P. S. Badwal, F. T. Ciacchi, V. Zelizko, Ionics 1998, 4, 25.

[20] G. H. Hsieh, W. H. Tuan, J. Mater. Sci. Lett. 2002, 21, 391.

[21] N. Gupta, P. Mallik, B. Basu, J. Alloys. Compd. 2004, 379, 228.

[22] N. Gupta, P. Mallik, M. H. Lewis, B. Basu, in Euro Ceramics Viii, Pts 1-3, Vol. 264-268, 2004, 817.

[23] J. Kondoh, H. Shiota, K. Kawachi, T. Nakatani, J. Alloys. Compd. 2004, 365, 253.

[24] G. R. Anstis, P. Chantikul, B. R. Lawn, D. B. Marshall, J. Am. Ceram. Soc. 1981, 64, 533.

[25] J. J. Kruzic, R. O. Ritchie, J. Am. Ceram. Soc. 2003, 86, 1433.

[26] D. R. Askeland, P. P. Phule, Essentials of Materials Science and Engineering, Thomson, Toronto Ontario Canada 2004.

[27] J. Kondoh, J. Alloys. Compd. 2004, 375, 270. 


\section{Supplementary Information}

Sintered samples where investigated using a Siemens D500 Bragg-Brentano X-ray diffractometer with $\mathrm{Cu} \mathrm{K}_{\alpha}$ with $\alpha_{1}$ and $\alpha_{2}$ weighted average radiation ( $\lambda=1.54178$ $\AA$ ). The instrument was operated with an accelerating voltage of $40 \mathrm{kV}$ and a filament current of $30 \mathrm{~mA}$. The goniometer settings were $20-120^{\circ} 2 \theta$ with a step size of $0.02^{\circ} 2 \theta$, the slit size $(1 / 2 / 3)$ used were $1^{\circ} / 1^{\circ} / 1^{\circ}$. Pattern investigation and Rietveld analysis was conducted using the software package Rietica 1.7.7 (1997). Powder diffraction of the hydrous cake through calcination up to $1000^{\circ} \mathrm{C}$ were obtained using an X-ray diffractometer incorporating a platinum resistance-strip heater, with an Inel CPS-120 curved, position-sensitive detector. The angular range of the detector is 120 deg $2 \theta$, facilitating rapid, simultaneous data accumulation. Data were collected in the reflection mode using Co K radiation operated at $35 \mathrm{kV}$ and $30 \mathrm{~mA}$. Datasets of $60 \mathrm{~s}$ in duration were collected in $10^{\circ} \mathrm{C}$ increments as the temperature was increased from room temperature to $1000^{\circ} \mathrm{C}$ and every $20^{\circ} \mathrm{C}$ whilst cooling. The Pt strip of the heater contained a small sample well measuring 20.0 x 7.0 x $0.4 \mathrm{~mm}$. Each sample was hand ground in a mortar and pestle with ethanol and was applied directly onto the Pt strip heater as a thick slurry.

The samples were milled in a 01HD Union Process (Akron Ohio) Szegvari Attritor system. The attritor had a $500 \mathrm{ml}$ volume with $0.8 \mathrm{~mm}$ diameter partially stabilised zirconia (PSZ) milling media, agitation was achieved using a PSZ attritor arm. Mill slip was made from $1 \mathrm{~kg}$ of calcined powder and milli-q water, the solids content was 45\%. A flow through system was used with the mill slip being gravity fed to the top of the attritor from an external tank. The slip then passed through the milling chamber 
and a pump, with an inlet at the bottom of the attritor, delivering the mill slip back to the top of the external tank closing the loop. Pump speed and gravity feed rate were matched so a constant level was kept in the attritor. Sampling and testing were conducted on a slip collected from the gravity feed discharge. The samples were milled until two consecutive PSD tests taken hourly returned a D90 of approximately $2 \mu \mathrm{m}$. The use of statistical measures in particle sizing is common within the chemical powder industry; the three most common measures that are used are the D90 being the $90^{\text {th }}$ percentile, D50 and D10, which are both the $50^{\text {th }}$ and $10^{\text {th }}$ percentile respectively.

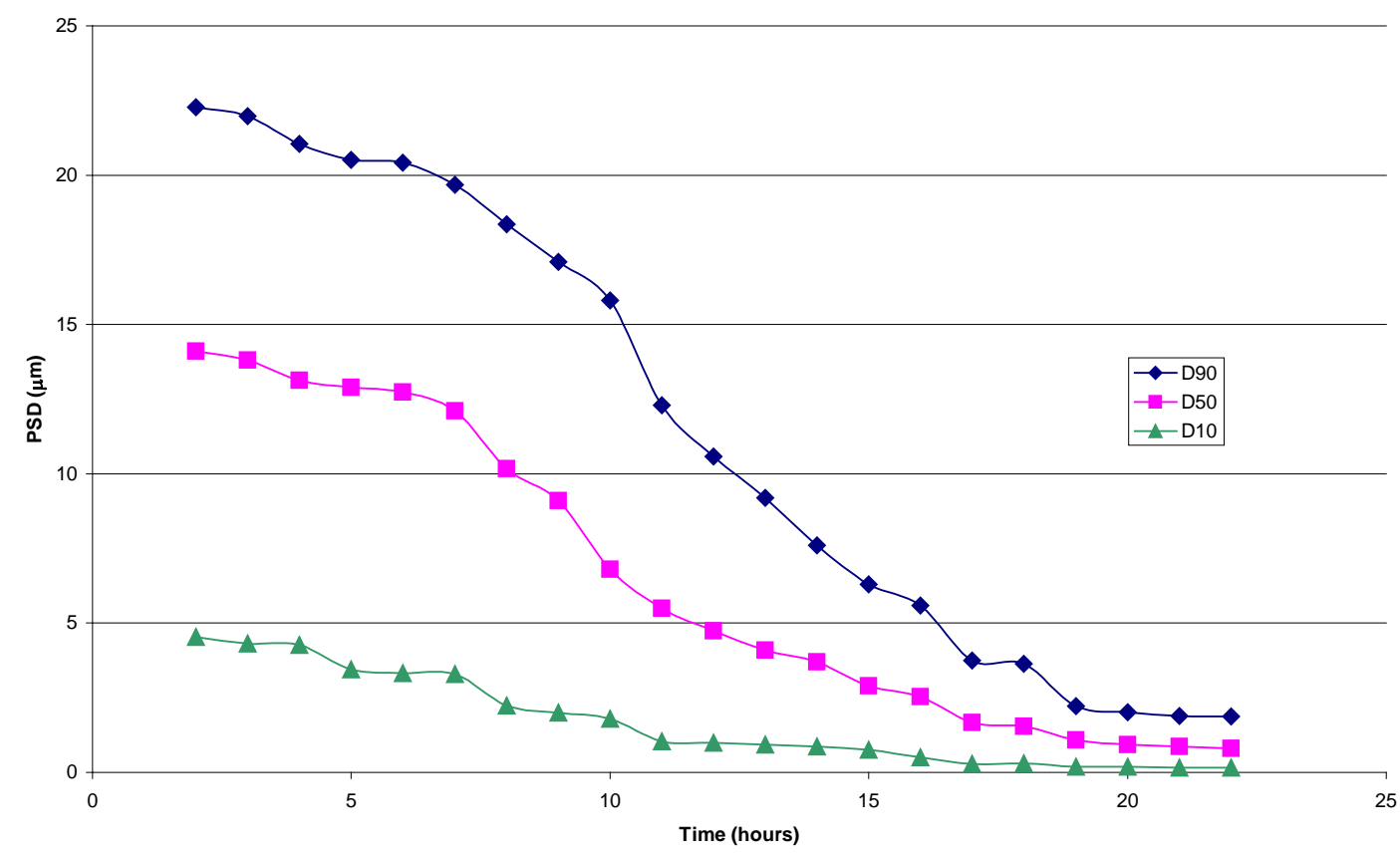

Figure S 1 pH 3 milling Curve 


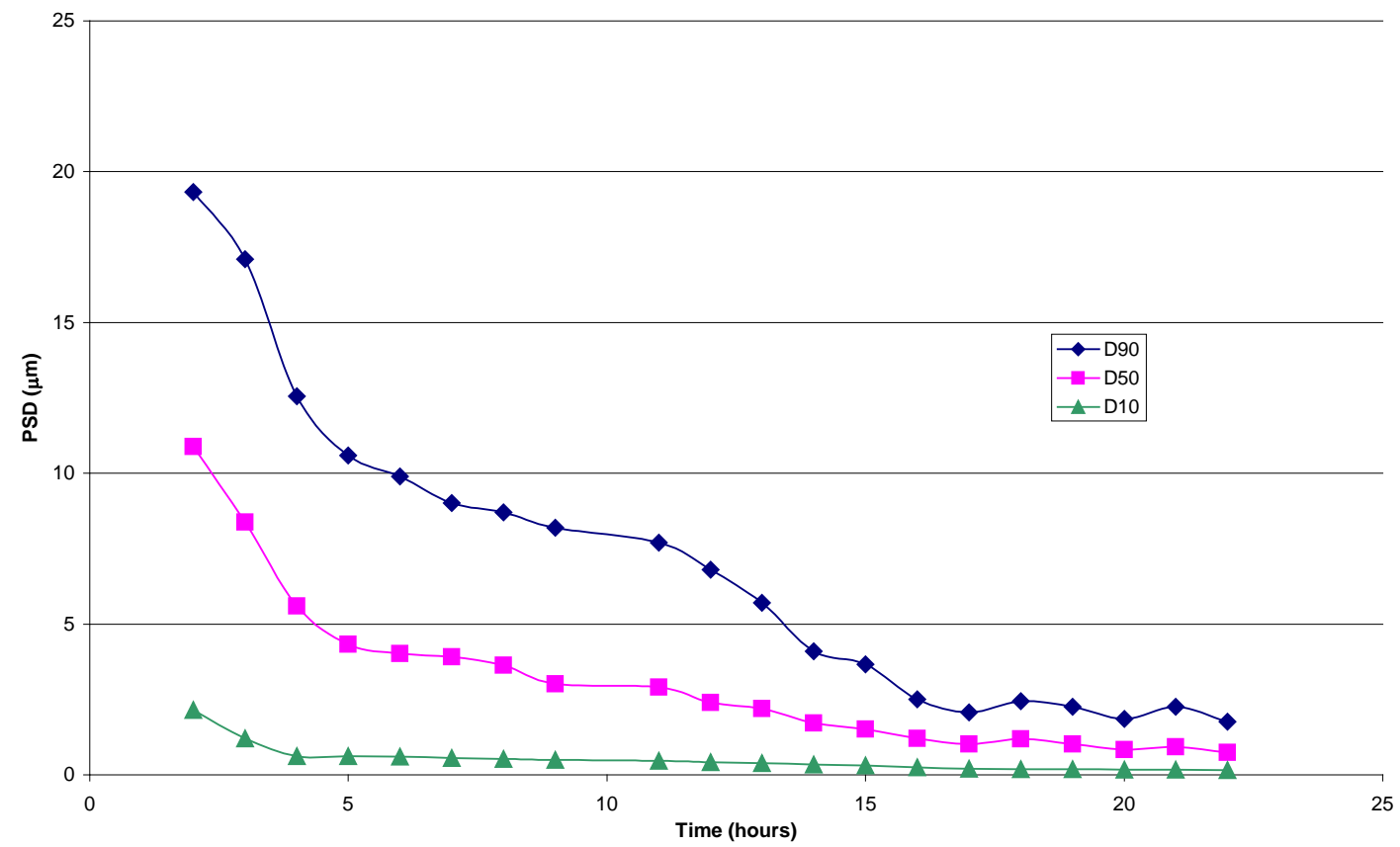

Figure S 2 pH 12 milling curve

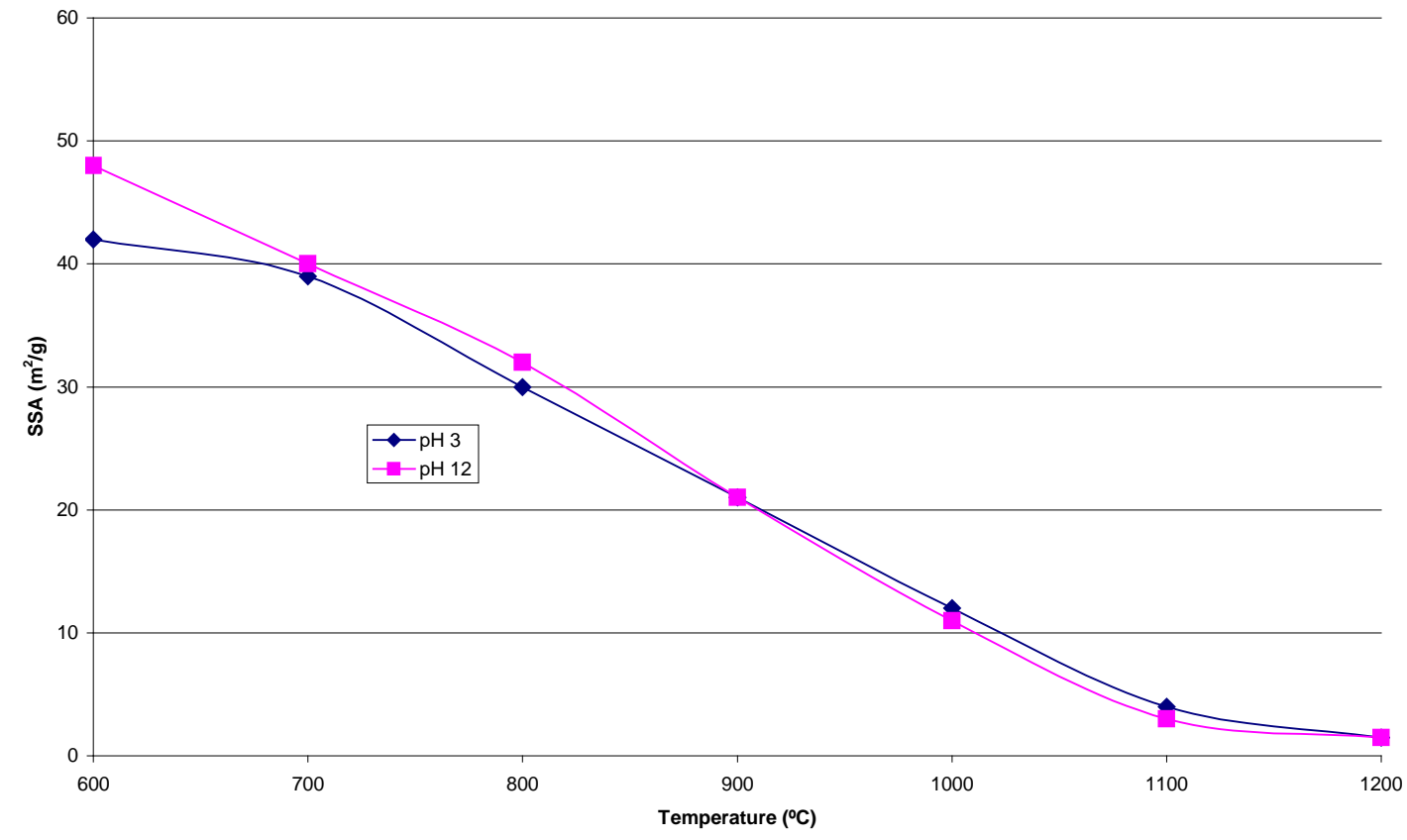

Figure S 3 SSA Variation with Calcination Temperature for $\mathrm{pH} 3$ and $\mathrm{pH} 12$ samples

Slurry suitable for spray drying was formed using the constituents listed in Table S 1 .

The products were mixed together using a TABULAR shaker mixer for 40 minutes 
then rolled for 24 hours in a plastic drum with alumina beads to break up any aggregates. The slurry was then spray dried with a Niro Mobile Minor using a two fluid nozzle. Spray drying is a method for drying slurries into homogeneous free flowing powders. It also allows the final spherical agglomerate particle size to be controlled.

Table S 1 Spray drying slurry constituents

\begin{tabular}{lc}
\hline Material & wt\% \\
\hline Zirconia powder & 45 \\
Distilled water & 52 \\
Dispex & 1 \\
Glycerol & 1 \\
Polyvinyl acetate & 1 \\
\hline
\end{tabular}

The feed slurry was mixed to produce a solids content of approximately $47 \%$ which was fed into the system at a controlled rate so that an outlet temperature of $105^{\circ} \mathrm{C}$ was retained for an inlet temperature of $350{ }^{\circ} \mathrm{C}$. The atomising air rate was set to the mid point of the rotameter with an air pressure of $7 \mathrm{Bar}(0.7 \mathrm{MPa})$.

Mahdjoub et. al. [28] discusses the effect of slurry formation upon the morphology of spray-dried zirconia yttria composites and lists conditions that produce misshapen agglomerates that result in powders that are not free flowing and are difficult to compact in subsequent processing. An investigation of the spray-dried powder shape was undertaken using SEM they both were found to be spherical with Figure S 4 being typical. 


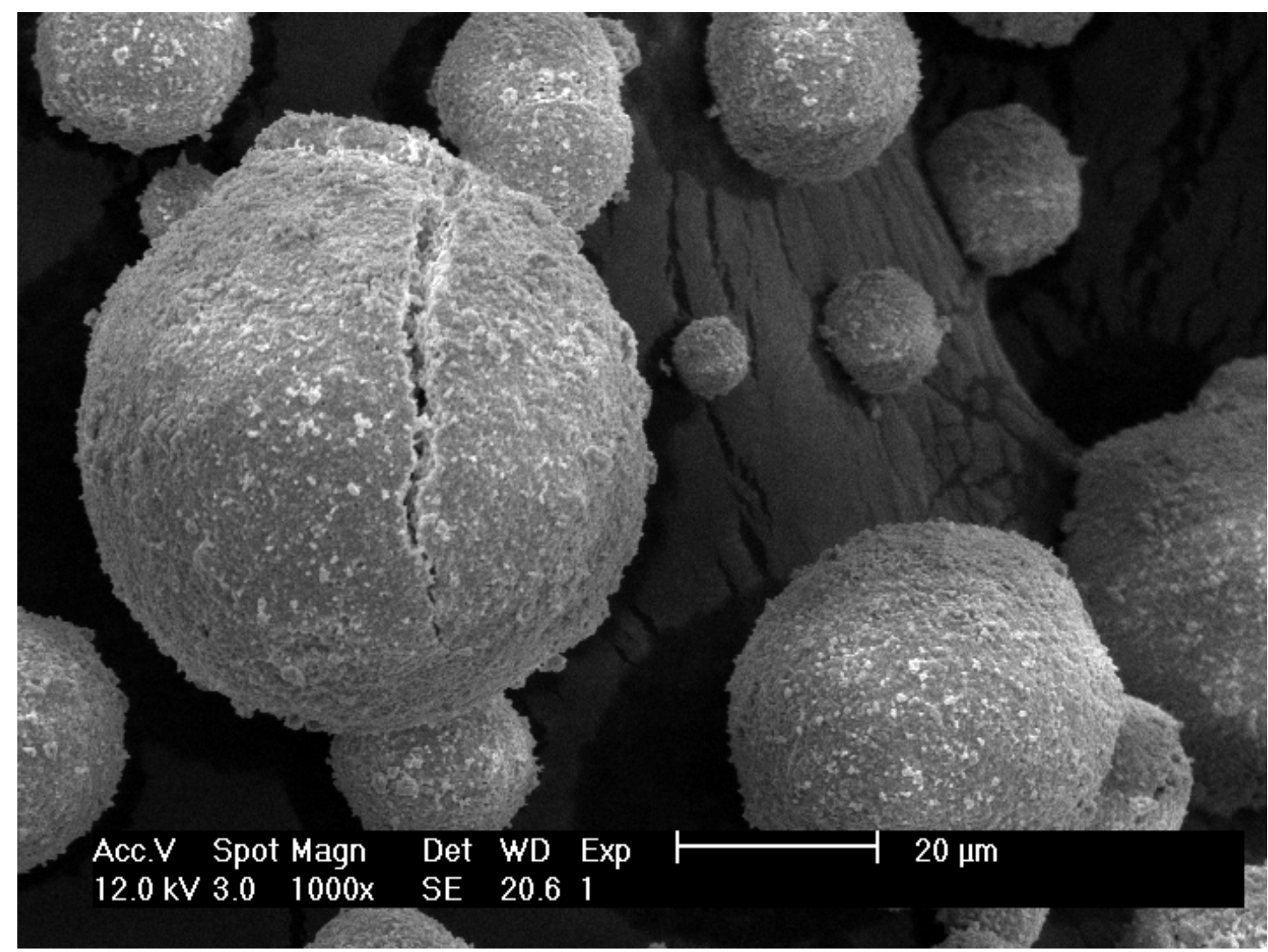

Figure S 4 SEM of spray-dried agglomerate (pH 3)

The following is a brief account of the procedures used in the testing.

All pellets and bars used in this testing were initially formed using a 316 SS die with stearic acid dissolved in methanol as a die lubricant. The die and powder was pressed at $30 \mathrm{MPa}$ with a dwell of approximately 30 seconds. The powder was removed from the die and bagged in standard balloons for cold isostatic pressing at $200 \mathrm{MPa}$.

All samples tested were fired using the same sintering regime, the firing regime used is a standard regime used for comparative testing and has not been optimised to find the best conditions for firing. The sintering profile is described in Table S 2 . 
Table S 2 Sintering regime

\begin{tabular}{|l|l|l|}
\hline Temperature & Time Taken & Rate \\
\hline $0^{\circ} \mathrm{C}$ to $30^{\circ} \mathrm{C}$ & $10 \mathrm{mins}$ & $3^{\circ} \mathrm{C} / \mathrm{min}$ \\
\hline $30^{\circ} \mathrm{C}$ to $400^{\circ} \mathrm{C}$ & $6 \mathrm{hrs} 10 \mathrm{mins}$ & $1^{\circ} \mathrm{C} / \mathrm{min}$ \\
\hline Dwell at $400^{\circ} \mathrm{C}$ & $30 \mathrm{mins}$ & \\
\hline $400^{\circ} \mathrm{C}$ to $1550^{\circ} \mathrm{C}$ & $9 \mathrm{hrs} 35 \mathrm{mins}$ & $2^{\circ} \mathrm{C} / \mathrm{min}$ \\
\hline Dwell at $1550^{\circ} \mathrm{C}$ & $3 \mathrm{hrs}$ & \\
\hline $1550^{\circ} \mathrm{C}$ to $30^{\circ} \mathrm{C}$ & $8 \mathrm{hrs} 27 \mathrm{mins}$ & $3^{\circ} \mathrm{C} / \mathrm{min}$ \\
\hline
\end{tabular}

The sintering was conducted in a muffle furnace with molybdenum di-silicide $\left(\mathrm{MoSi}_{2}\right)$ heating elements in a standard air atmosphere.

All physical characterisation was conducted using the following well documented procedures

1) Hardness (Vickers indentation ASTM E 384-89 (1997)) [29]

2) Toughness ( $\mathrm{K}_{1 \mathrm{c}}$ Vickers crack propagation method as per Anstis et al.) [24]

3) Modulus Of Rupture (MOR ASTM method C1161-94 (1996))[30]

4) Grain sizing (Abrahm's three ring method with ASTM E-112)[31]

5) Linear Shrinkage

6) Green and sintered density (ASTM C20 (1992)) 
Samples used in Hardness, toughness and grain sizing after pressing/firing were polished to $1 \mu \mathrm{m}$ finish using a Struers Pedimat with diamond polish. The polishing consisted of mounting in epoxy resin and grinding using a $40 \mu \mathrm{m}$ Pedimat pad until flat. The remaining polishing at 9, 6, 3 and $1 \mu \mathrm{m}$ was for 30 minutes with a force of $20 \mathrm{~N}$.

MOR test pieces were diamond machined parallel to the specimen axis to an approximately $6 \mu \mathrm{m}$, then polished to a $3 \mu \mathrm{m}$ finish with diamond polish using a Struers Pedimat.

The Vickers microhardness test defined in ASTM E 384-89 (1997) was used to determine the hardness of the ZY3. A Zwick hardness tester type 3212B was used for hardness measurements. Indentations were made with a $1 \mathrm{~kg}$ load applied for 20 seconds. The indentation was inspected using the optical and digital system of a Nikon Eclipse ME600 materials microscope. The objective lens used was 50x magnification resulting in an effective magnification of 500x. Five replicates of each composition were tested with each sample being tested a number of times. An Asahi standardised block for hardness (Test certificate number 75308) was used prior to testing the zirconia samples the values returned were within the calibration range (hardness value of $964.3 \pm 4 \%$ ).

Toughness is defined as a measure of the energy that a material is able to absorb before fracture [32]. By measuring the crack length initiated by a hardness test 
indentation and using the formula below the value of the fracture toughness can be determined.

$$
k_{c}=0.16 H v \sqrt{\frac{d}{2}}\left(\frac{c}{d}\right)^{-\frac{3}{2}}
$$

Where $H v$ is the hardness and $d$ is the mean distance of the indent diagonals and $c$ is the mean distance of the fracture diagonals [24].

Modulus of rupture (MOR), preformed to ASTM Designation C1161-94 (1996) also known as the bend strength, is the maximum stress or stress at fracture was developed using the four point bending test. Samples were $55 \mathrm{~mm} \times 3 \mathrm{~mm} \times 4 \mathrm{~mm}$ with a chamfer on one of the corners as per the ASTM. Breaks were made using a Lloyds 6000R test instrument.

The grain sizing was conducted using the Abrams three circle method in line with ASTM E-112. The samples were thermally etched by heating with a ramp rate of 1 ${ }^{\circ} \mathrm{C} /$ minute to $1500{ }^{\circ} \mathrm{C}$ with a dwell of 30 minutes. Imaging was conducted using a Phillips XL30 tungsten filament SEM. The SEM was operated at $25 \mathrm{kV}$ secondary electron imaging at a magnification of either 1000 or 1500x dependent on particle size.

The green density of a pressed pellet was determined by a measurement of its dimensions to ascertain its volume and a measurement of its weight. Dividing the pellets weight by its volume allows the density to be calculated. The radius and height of the pellet was ascertained by the use of vernier callipers or a micrometer. The 
measurements of the dimensions of the pellet were taken at three different places on the pellet and an average used for the calculation. The pellet was weighed to four decimal places on a balance.

The samples were fired in accordance with the firing regime as specified in the relevant section of this document. The sintered density of the pellet was obtained by Archimedes principle.

The linear shrinkage, a measure of the linear dimensional change during firing, was developed by measuring the green powder dimensions and then measuring dimensions of the fired part.

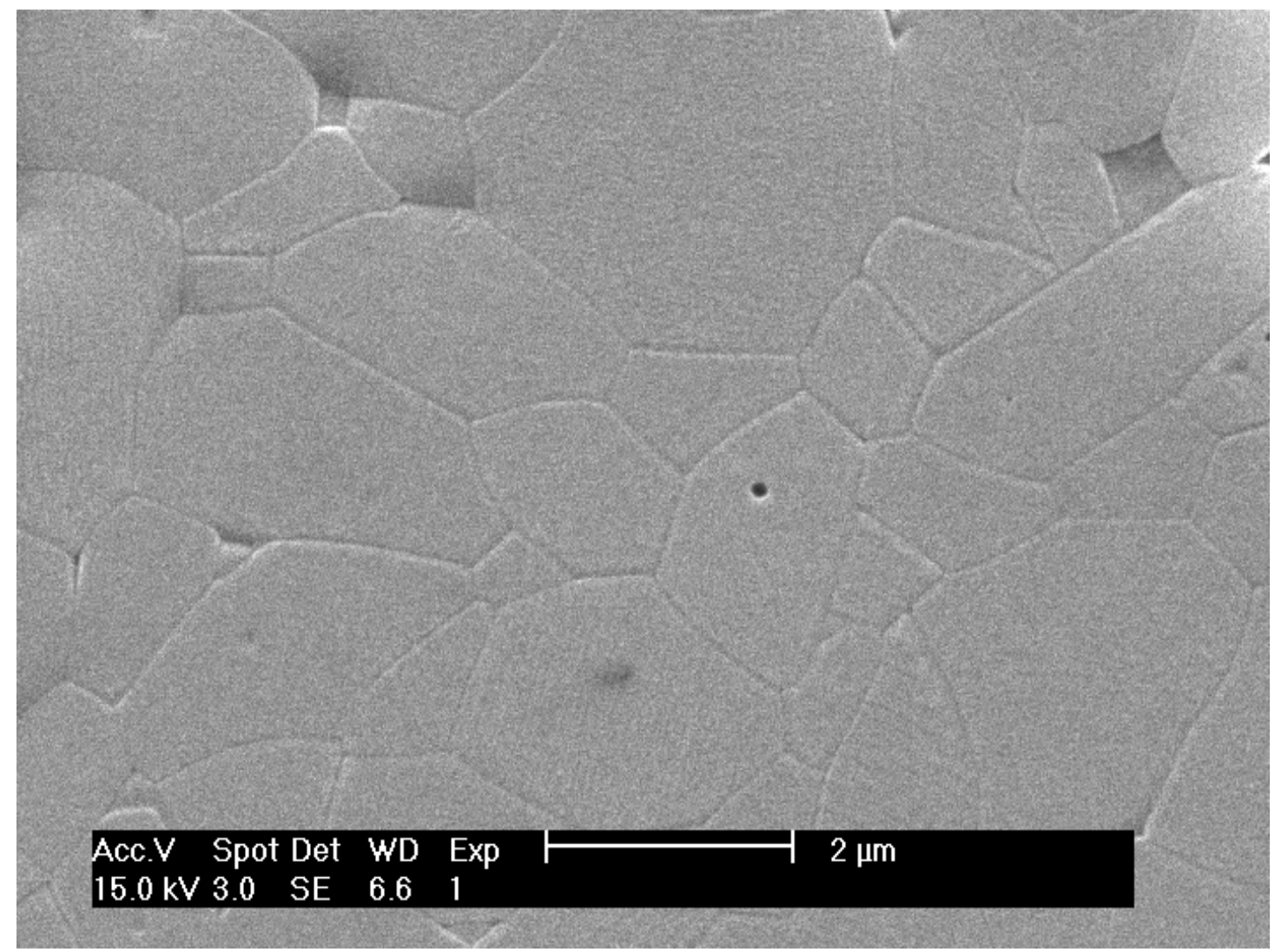

Figure S 5 SEM micrograph used for grain sizing pH 12 Typical. 


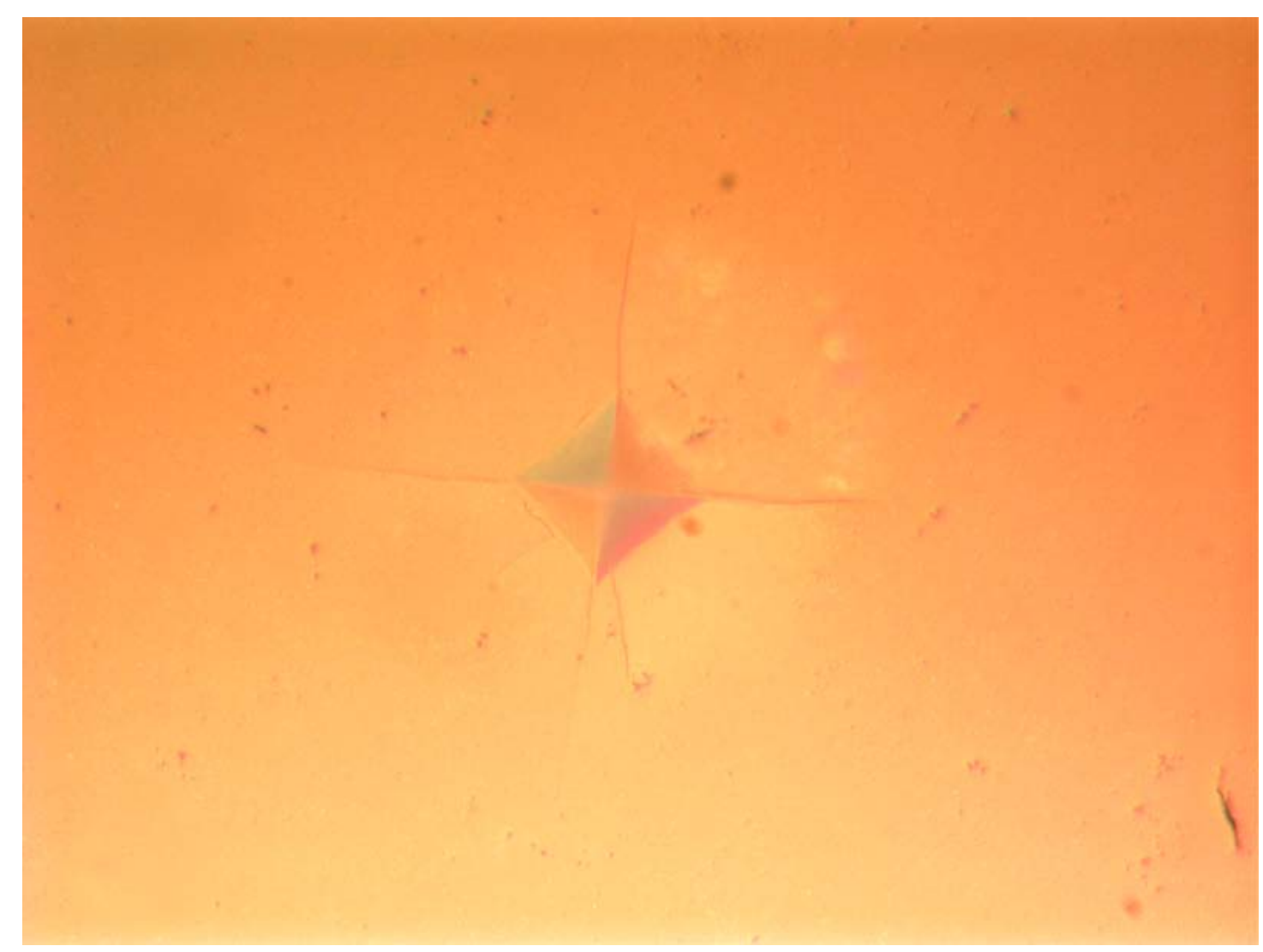

Figure S 6 Optical micrograph showing a Vickers indentation. 


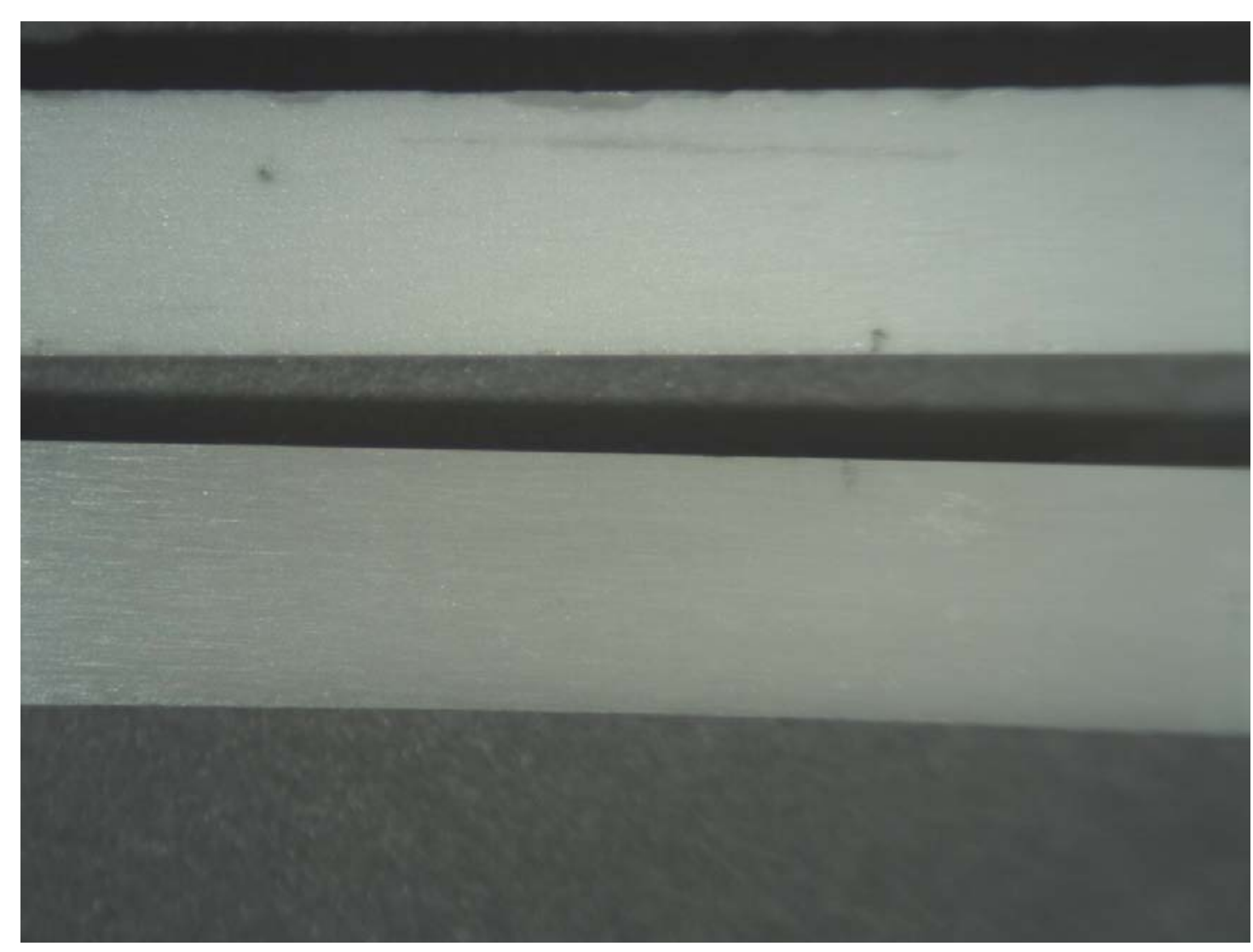

Figure S 7 Optical Micrograph of 2 MOR bars showing difference in optical properties

[28] H. Mahdjoub, P. Roy, C. Filiatre, G. Bertrand, C. Coddet, J. Eur. Ceram. Soc. 2003, 23, 1637.

[29] ASTM, ASTM E 384-89 1990, 'Standard Test Method for Microhardness of Materials', , Vol. 1990, ASTM Standards, 1990.

[30] ASTM C 1161-94 1996, ASTM C 1161-94 1996, 'Stanard test method for flexural strength of advanced ceramics at ambient temperature', Vol. 03.01, ASTM Standards, 1996.

[31] ASTM C 112-96 1999, ASTM C 112-96 1999, 'Standard Test Method for Determining Average Grain Size’, , Vol. 03.01, 1999.

[32] J. Callister, W.D. , Materials Science and Engineering: An Introduction 4th edn, John Wiley \& Sons, Inc., New York. 1997. 